\title{
EFFICACY OF INTRATHECAL LEVOBUPIVACAINE AND BUPIVACAINE FOR CAESAREAN SECTION- A COMPARATIVE STUDY
}

\author{
Amalendu Bikas Chatterjee ${ }^{1}$, Debaleena Jana², Swarup Dutta 3 , Madhab Chandra Mandal4, Asish Kumar Paul ${ }^{5}$ \\ 1 Professor, Department of Anaesthesiology, Bankura Sammilani Medical College, Bankura, West Bengal. \\ ${ }^{2}$ Senior Resident, Department of Anaesthesiology, Midnapore Medical College, Midnapore, West Bengal. \\ ${ }^{3}$ Assistant Professor, Department of Anaesthesiology, Bankura Sammilani Medical College, Bankura, West Bengal. \\ ${ }^{4}$ Medical Officer, Department of Anaesthesiology, Asansol District Hospital, West Bengal. \\ ${ }^{5}$ Specialist MO, Department of Anaesthesiology, Asansol Super Speciality Hospital, West Bengal.
}

\begin{abstract}
BACKGROUND

Levobupivacaine is the S (-) isomer of bupivacaine, developed as an alternative to bupivacaine for regional anaesthesia after the evidence of its less cardiotoxicity and neurotoxicity. The present study was undertaken to compare the quality of sensory and motor block, haemodynamic changes and side effects if any, following intrathecal levobupivacaine and hyperbaric bupivacaine, in parturients undergoing elective caesarean section.
\end{abstract}

\section{MATERIALS AND METHODS}

Ninety parturients of ASA status I or II for the elective caesarean section were enrolled in this prospective randomised, doubleblinded study. The parturients were randomly assigned to two groups with patients in Group L ( $\mathrm{n}=45)$ and Group B (n = 45). Subarachnoid block was performed with $2.5 \mathrm{~mL}$ of $0.5 \%$ isobaric levobupivacaine in Group L and $2.5 \mathrm{~mL}$ of $0.5 \%$ hyperbaric bupivacaine in Group B. Characteristics of sensory and motor block were assessed with pinprick using Hollmen scale and modified Bromage scale, respectively. Side effects such as hypotension, bradycardia, nausea, and vomiting were recorded. Observed data were analysed with the help of Statistical Package for Social Sciences (IBM SPSS software version 20).

\section{RESULTS}

The two study groups were comparable in terms of age, height, body weight and duration of surgery. Patients who received intrathecal levobupivacaine (Group L) experienced effective spinal anaesthesia with significantly late onset of sensory and motor block (5.72 min. vs. $5.13 \mathrm{~min}$; p=0.001 and $7.0 \mathrm{~min}$. vs. $5.47 \mathrm{~min}$.; p=0.001), but longer duration of analgesia (124.49 min. vs. 120.58 min.; $\mathrm{p}=0.001$ ) in comparison to the patients who received intrathecal bupivacaine (Group B). Few patients experienced shivering, few reported nausea and vomiting in both groups intraoperatively.

\section{CONCLUSION}

Intrathecal levobupivacaine seems to be an effective alternative to intrathecal bupivacaine in infra-umbilical surgeries like caesarean section with reduced toxic potential and excellent quality of analgesia.

\section{KEYWORDS}

Caesarean Section, Hyperbaric Bupivacaine, Intrathecal, Levobupivacaine.

HOW TO CITE THIS ARTICLE: Chatterjee AB, Jana D, Dutta S, et al. Efficacy of intrathecal levobupivacaine and bupivacaine for caesarean section- A comparative study. J. Evolution Med. Dent. Sci. 2017;6(95):6998-7002, DOI: 10.14260/jemds/2017/1519

\section{BACKGROUND \\ MATERIALS AND METHODS}

Central neuraxial techniques are an indispensable part of modern anaesthetic practice, providing alternatives to general anaesthesia whenever appropriate. [1] [2] Subarachnoid block is the most commonly administered neuraxial anaesthesia for caesarean delivery because it is easy to perform. Bupivacaine is a well-established long-acting local anaesthetic which like all amide anaesthetics has been associated with cardiac toxicity when used in high concentration or when accidentally administered intravascularly. Levobupivacaine is the $S(-)$ isomer of bupivacaine, developed as an alternative to bupivacaine, after the evidence of its less cardiotoxicity and neurotoxicity. $[3,4,5,6]$

'Financial or Other Competing Interest': None.

Submission 15-11-2017, Peer Review 09-12-2017,

Acceptance 15-12-2017, Published 23-12-2017.

Corresponding Author:

Dr. Swarup Dutta,

Friends Residency,

Keshiakole, Bankura-722155, West Bengal, India.

E-mail: drsdatta66@gmail.com

DOI: $10.14260 /$ jemds $/ 2017 / 1519$

This prospective randomised, double-blinded study was conducted in the Department of Obstetrics and Gynaecology, BS Medical College, Bankura. After getting institutional ethics committee approval and written informed consent from all the parturients, a total of 90 parturients who met the inclusion criteria undergoing caesarean section under spinal anaesthesia, were enrolled for study.

To estimate sample size, thorough review of literature of related text books were done before estimating sample size for the study. Searches included standard text books and internet indexing services such as PubMed, Medline and Index Medicus. Based on literature data and using the Power and sample size calculation software (version 2.1.30, DuPont \& Plummer, February 2003) with $\alpha$-error of 0.05 , $\beta$-error of 0.9 , acceptable mean difference of 5.85 unit (min), expected standard deviation of 10 and non-inferiority margin 5 units, a minimum sample size of 37 subjects was required per group for a twotailed hypothesis. We decided to recruit 45 patients to each group to make up $10 \%$ dropouts from the study groups. Inclusion criteria being ASA physical status I \& II patients selected for elective caesarean section. Exclusion criteria being 
patient's refusal, known cardiac diseases (like ischaemic heart disease, heart failure, valvular heart diseases and conduction disorder); known renal, hepatic, coagulation disorder; any neurological disorder; patients using beta blocker, antipsychotic drugs, sedatives; spinal deformities; trauma and local infection; allergy to aminoamide local anaesthetic; preeclampsia; eclampsia; twin pregnancy.

Onset of sensory block was assessed by pinprick with $23 \mathrm{G}$ needle using Hollmen scale[7] [0=ability to appreciate a pinprick as sharp, $1=$ ability to appreciate a pinprick as less sharp, 2=inability to appreciate a pinprick as sharp (analgesia), 3=inability to appreciate a pin touching]. Onset and degree of motor block by Modified Bromage Scale $(0=$ able to flex whole lower limb at hip, $1=$ able to flex knee but unable to flex at hip, $2=$ able to flex ankle but unable to flex knee, $3=$ no movement of lower limb). Duration of analgesia by the end point when the first rescue analgesic required, was assessed by using 0-10 linear Visual Analogue Scale and haemodynamic variables (SBP, DBP, MAP, HR) monitored using multichannel monitors. Study tools: Hollmen Scale, VAS, Modified Bromage Scale, Pulse Oximeter, NIBP monitor.

Complete pre-anaesthetic evaluation was performed in each parturient including detailed history taking, thorough physical check-up (weight, height of all the patients) and assessment of spine, airway examination and assessment and routine preoperative investigations. All parturients received ranitidine $150 \mathrm{mg}$ orally the night before and on the morning of surgery and parturients were kept fasting from midnight before surgery. Using table of random number, 90 patients were allocated into two groups (45 in each group).

In this prospective, double-blinded study, 90 parturients belonging to ASA physical status I and II were randomly allocated into two groups, Group $\mathrm{L}(\mathrm{n}=45)$ received $0.5 \%$ isobaric levobupivacaine $2.5 \mathrm{~mL}(12.5 \mathrm{mg})$ and Group $\mathrm{B}(\mathrm{n}=45)$ received $0.5 \%$ hyperbaric bupivacaine $2.5 \mathrm{~mL}(12.5 \mathrm{mg})$. The study drugs were prepared by an anaesthesiologist who was not otherwise involved in the study. The anaesthesiologist performing the block and observing the effects were also blinded to the treatment group.

Following arrival in the anaesthetic room, IV access was established with $18 \mathrm{G}$ cannula in a large vein on the dorsum of hand and prehydration was done with $10 \mathrm{~mL}$ per kg lactated Ringer's solution. Anaesthesia machine, airway equipment, difficult airway cart, drugs for resuscitation and general anaesthesia were kept ready in hand before starting the procedure. ASA standard monitors were connected for $\mathrm{HR}, \mathrm{O}_{2}$ saturation, NIBP and ECG monitoring. Patients were placed in the sitting position. The overlying skin was prepared with povidone-iodine spirit, followed by antiseptic draping. After proper identification of the space, subarachnoid block was given at the level of $\mathrm{L}_{3-4}$ interspace using a $25 \mathrm{G}$ Quincke point needle. The correct needle placement was identified with the free flow of cerebrospinal fluid (CSF) and $2.5 \mathrm{~mL}$ of study drug

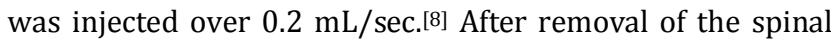
needle, patients were turned to a 15-20 degree left lateral supine position. Oxygen $5 \mathrm{~L} / \mathrm{min}$. was administered via a facial mask.

Haemodynamic monitoring was started immediately. The level of sensory block was determined bilaterally by response to pinprick using Hollmen Scale in the anterior axillary line. Sensory block was assessed at $2 \mathrm{~min}$. post injection and at 1 min. intervals thereafter and permission to perform operations was given once a T4-T6 level had been achieved. The onset time of sensory block was recorded. The motor block was determined by modified Bromage Scale at $2 \mathrm{~min}$. post injection and at $1 \mathrm{~min}$. intervals thereafter. The onset time and highest scale of motor block was recorded. Heart rate and blood pressure was recorded using standard non-invasive monitors before intrathecal injection and then every $5 \mathrm{~min}$. interval till the end of surgery. Operation duration was recorded as time until end of operation after administration of local anaesthetics. After the completion of surgery, patients were shifted to PACU (post anaesthesia care unit). Assessments of sensory regression was continued at 30-min. intervals following the completion of surgery until it regressed up to T10 dermatome and duration of analgesia was monitored by VAS when the patient required the first rescue analgesic. Rescue analgesic was administered when patient had a VAS Score $>3$ in the form of Injection Diclofenac sodium 75 mg intramuscularly.

Side effects such as nausea, vomiting, headache, hypotension, bradycardia and shivering were recorded. Hypotension (defined as systolic blood pressure $<90 \mathrm{mmHg}$ or a decrease of $20 \%$ below the baseline level in MAP) was treated with intravenous mephentermine 3-9 mg or intravenous phenylephrine $50 \mu \mathrm{g}$ and additional lactated Ringer's solution. $[9,10$,$] Bradycardia defined as heart rate <50$ bpm was treated with intravenous atropine 0.3-0.6 mg Patients were followed up daily for any adverse events during their hospital stay.

\section{Plan for Analysis of Data}

All raw data were entered into a predesigned excel spreadsheet and analysed using standard statistical software (IBM SPSS version 20). Numerical data was expressed as means, medians and standard deviation of mean. Categorical data was expressed as percentages. Numerical data between two groups which was normally distributed was analysed using Student's independent two tailed t-test. A p value of less than 0.05 was considered statistically significant.

\section{RESULTS}

All the 90 patients who were enrolled in this double-blinded, randomised comparative study, completed the study. There was no dropout and the study results are shown below. Table 1 shows distribution of demographic profile in two study groups. There was no statistically significant difference in age, weight or height distribution among the study groups as ' $\mathrm{p}$ ' value $>0.05$ and hence the groups were comparable to each other in terms of age, weight and height. Table 2 shows distribution of onset of sensory block, onset of motor block, duration of surgery and duration of analgesia in two study groups. There was statistically significant difference in onset of sensory block and motor block and duration of analgesia and no statistically significant difference in duration of surgery. Onset of sensory block is faster in B group (5.13 \pm $0.87)$ than group L $(5.72 \pm 1.10)$. Onset of motor block is faster in B group $(5.47 \pm 0.75)$ than $\mathrm{L}(7.00 \pm 0.95)$. There was no significant difference in duration of surgery in both the groups. The duration of analgesia (min.) was significantly more in L group than in B group, as ' $p$ ' value was $<0.05$. Table 3 shows statistically significant difference between the patients of Group L and Group B as p value was $<0.05$ (student's independent t-test), found in pulse rates (Table 3) in any time 
of measurement except baseline and at $30 \mathrm{~min}$. The statistically significant difference in $p$ value ( $p$ value $<0.05$ ) by student's independent t-test was found in mean arterial pressure (Table 3) at any time of measurement except baseline and 20 minutes. Side effects- nausea, vomiting, hypotension, bradycardia were more in B group (Table 4).

\begin{tabular}{|c|c|c|c|}
\hline Variables & Group L, (n=45) & Group B, (n=45) & P value \\
\hline Age (years) & $23.22 \pm 2.6$ & $23.11 \pm 2.4$ & 0.83 \\
\hline Weight (Kg) & $62.82 \pm 2.97$ & $63.29 \pm 3.77$ & 0.51 \\
\hline Height $(\mathrm{cm})$ & $153.69 \pm 3.88$ & $153.84 \pm 3.82$ & 0.84 \\
\hline
\end{tabular}

Table 1. Demographic Features of the Patients

Analysed with independent $t$ test. Values expressed in mean $\pm \mathrm{SD} ; \mathrm{p}<0.05$ is taken as significant.

\begin{tabular}{|c|c|c|c|}
\hline Variables & Group L, (n=45) & Group B, (n=45) & P value \\
\hline $\begin{array}{c}\text { onset of } \\
\text { sensory block } \\
\text { (min.) }\end{array}$ & $5.72 \pm 1.10$ & $5.13 \pm 0.87$ & 0.001 \\
\hline $\begin{array}{c}\text { onset of motor } \\
\text { block (min.) }\end{array}$ & $7.00 \pm 0.95$ & $5.47 \pm 0.75$ & 0.001 \\
\hline $\begin{array}{c}\text { duration of } \\
\text { surgery (min.) }\end{array}$ & $44.47 \pm 2.42$ & $44,18 \pm 2.76$ & 0.60 \\
\hline $\begin{array}{c}\text { Duration of } \\
\text { analgesia } \\
\text { (min.) }\end{array}$ & $124.49 \pm 2.64$ & $120.58 \pm 2.51$ & 0.001 \\
\hline $\begin{array}{c}\text { Table 2. Onset of Sensory Block, Onset of Motor Block, } \\
\text { Duration of Surgery, Duration of Analgesia }\end{array}$ \\
\hline
\end{tabular}

Analysed with independent $t$ test. Values expressed in mean \pm SD; $p<0.05$ is taken as significant.

\begin{tabular}{|c|c|c|c|c|c|c|}
\hline & 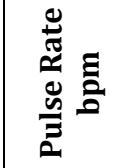 & & & $\sum \underbrace{\stackrel{000}{\Xi}}$ & & \\
\hline 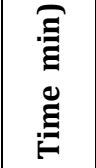 & 泀 & 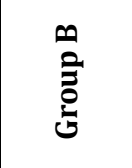 & $\begin{array}{l}0 \\
\frac{0}{\pi} \\
2 \\
0\end{array}$ & $\overrightarrow{0}$ & 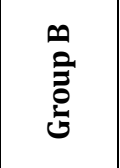 & 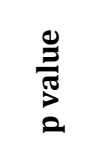 \\
\hline \begin{tabular}{|c|} 
Baseli \\
ne
\end{tabular} & $\begin{array}{c}106.33 \pm \\
7.58\end{array}$ & $\begin{array}{c}105.20 \pm \\
6.5\end{array}$ & 0.43 & \begin{tabular}{|c|}
$89.11 \pm$ \\
5.76
\end{tabular} & \begin{tabular}{|c|}
$89.80 \pm$ \\
6.58
\end{tabular} & 0.59 \\
\hline 5 & $\begin{array}{c}78.93 \pm \\
11.47\end{array}$ & $\begin{array}{c}106.40 \pm \\
.57\end{array}$ & 0.001 & \begin{tabular}{|c|}
$80.09 \pm$ \\
4.94
\end{tabular} & \begin{tabular}{|c|}
$92.13 \pm$ \\
4.13
\end{tabular} & 0.001 \\
\hline 10 & $\begin{array}{c}71.71 \pm \\
9.21\end{array}$ & $\begin{array}{c}97.18 \pm \\
5.35\end{array}$ & 0.001 & \begin{tabular}{|c|}
$74.05 \pm$ \\
6.72
\end{tabular} & \begin{tabular}{|c|}
$89.31 \pm$ \\
6.54
\end{tabular} & 0.001 \\
\hline 15 & $\begin{array}{c}72.40 \pm \\
7.43 \\
\end{array}$ & \begin{tabular}{|c|}
$93.71 \pm$ \\
5.02 \\
\end{tabular} & 0.001 & \begin{tabular}{|c|}
$78.78 \pm$ \\
4.05 \\
\end{tabular} & \begin{tabular}{|c|}
$84.91 \pm$ \\
6.41 \\
\end{tabular} & 0.001 \\
\hline 20 & $\begin{array}{c}84.18 \pm \\
7.65 \\
\end{array}$ & $\begin{array}{c}91.51 \pm \\
5.05 \\
\end{array}$ & 0.001 & \begin{tabular}{|c|}
$75.36 \pm$ \\
4.16 \\
\end{tabular} & \begin{tabular}{|c|}
$76.89 \pm$ \\
7.68 \\
\end{tabular} & 0.24 \\
\hline 25 & $\begin{array}{c}73.73 \pm \\
7.93\end{array}$ & $\begin{array}{c}85.91 \pm \\
9.98\end{array}$ & 0.001 & \begin{tabular}{|c|}
$68.40 \pm$ \\
4.92
\end{tabular} & \begin{tabular}{|c|}
$79.51 \pm$ \\
8.01
\end{tabular} & 0.001 \\
\hline 30 & $\begin{array}{c}80.31 \pm \\
14.27 \\
\end{array}$ & $\begin{array}{c}82.58 \pm \\
10.97 \\
\end{array}$ & 0.40 & \begin{tabular}{|c|}
$75.00 \pm$ \\
6.60 \\
\end{tabular} & \begin{tabular}{|c|}
$78.11 \pm$ \\
9.40 \\
\end{tabular} & 0.07 \\
\hline 45 & $\begin{array}{c}73.98 \pm \\
6.75\end{array}$ & $\begin{array}{l}81.62 \\
\pm 6.11 \\
\end{array}$ & 0.001 & \begin{tabular}{|c|}
$74.80 \pm$ \\
5.48 \\
\end{tabular} & \begin{tabular}{|c|}
$85.36 \pm$ \\
9.60 \\
\end{tabular} & 0.001 \\
\hline 60 & $\begin{array}{c}75.04 \pm \\
6.46\end{array}$ & $\begin{array}{c}80.07 \pm \\
3.55\end{array}$ & 0.001 & \begin{tabular}{|c|}
$75.44 \pm$ \\
6.02
\end{tabular} & \begin{tabular}{|c|}
$90.02 \pm$ \\
2.98
\end{tabular} & 0.001 \\
\hline & e 3. Com & rison & 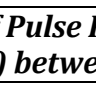 & e an & ean $\mathrm{Ar}$ & \\
\hline
\end{tabular}

Analysed with independent $t$ test. Values expressed in mean $\pm \mathrm{SD} ; \mathrm{p}<0.05$ is taken as significant.

\begin{tabular}{|c|c|c|c|}
\hline Side Effects & Group- I & Group- B & Total \\
\hline $\begin{array}{c}\text { Nausea \& } \\
\text { Vomiting }\end{array}$ & $4(8.8 \%)$ & $5(11.11 \%)$ & $9(10 \%)$ \\
\hline Shivering & $3(6.66 \%)$ & $4(8.88 \%)$ & $7(7.77 \%)$ \\
\hline Hypotension & $6(13.33 \%)$ & $8(17.77 \%)$ & $14(15.55 \%)$ \\
\hline Bradycardia & $2(4.44 \%)$ & $4(8.88 \%)$ & $6(6.66 \%)$ \\
\hline \multicolumn{4}{|c|}{ Table 4. Comparison of Side Effects between the Two } \\
Groups \\
\hline
\end{tabular}

\section{DISCUSSION}

Regional anaesthesia techniques are increasingly preferred for caesarean section compared to general anaesthesia. Regional anaesthesia has several advantages over general anaesthesia like decrease in stress response to surgery, improved postoperative analgesia, decreased incidence of nausea and vomiting, less respiratory and cardiac depression. Spinal anaesthesia is one kind of regional anaesthesia that provides benefits in the form of an extended effect on analgesia and reduced postoperative morbidity.[8, 9] With small amount of drug, systemic and pharmacologic effects are avoided, a deep surgical anaesthesia is obtained, and a safer, beneficial, and comfortable anaesthesia is provided for the mother and child compared to other techniques. Local anaesthetic, bupivacaine, acts mainly by blockade of voltage gated $\mathrm{Na}^{+}$channels in the axonal membrane, and possibly, a further effect on presynaptic inhibition of $\mathrm{Ca}^{++}$channels.[11] It is a wellestablished long-acting local anaesthetic which like all amide anaesthetics has been associated with cardiac toxicity when used in high concentration or when accidentally administered intravascularly. It has faster onset and reliability but has more chance of cardiotoxicity and neurotoxicity and needs longer duration of CPR in case of accidental vascular invasion.[12] $\mathrm{A}$ number of studies suggest that levobupivacaine, the pure L (-) enantiomer of bupivacaine is associated with less central nervous system and cardiac toxicity with comparable anaesthetic and analgesic property.

The present study was undertaken to compare the onset and duration of effective anaesthesia and analgesia. The comparison of clinical efficacy of group-L and group- $B$, in terms of onset and duration of analgesia, was assessed along with pulse rate, blood pressure (SBP, DBP, MAP) at regular intervals throughout the perioperative period in elective caesarean delivery.

In our study, the demographic profiles were comparable for age, weight and height in both the groups (Table 1).

Table 2 shows the duration of surgery performed in two groups. Applying appropriate statistical test, it was concluded that the two groups were comparable $(p=0.60)$ in terms of duration of surgery.

Table 2 shows the time for onset of sensory block and motor block in the two groups. The mean onset of sensory block to reach $\mathrm{T}_{6}$ in Group $\mathrm{L}$ was $5.72 \pm 1.10$ minutes and in Group B was $5.13 \pm 0.87$ minutes. Appropriate statistical test shows significant difference $(\mathrm{p}=0.00)$ in the onset of sensory block between the two groups. The mean onset time of motor block to maximum level in Group L were $7.00 \pm 0.95$ minutes and in Group B were $5.47 \pm 0.75$ minutes. With appropriate statistical test, $p$ value became 0.00 . Hence, it shows that there was statistical significant difference as $p$ is $<0.05$ in the time of 
onset of motor block between the patients in Group L and Group B.

In 2012, Turkmen A, Moralar DG, Ali A, Altan A[12] in a prospective study on 50 pregnant mothers undergoing caesarean section who received either bupivacaine $(0.5 \%) 7.5$ $\mathrm{mg}+$ fentanyl $15 \mathrm{mcg}$ or levobupivacaine $(0.5 \%) 7.5 \mathrm{mg}$ intrathecally concluded that time to sensory and maximum motor block was shorter in the bupivacaine + fentanyl group but longer duration of analgesia in the levobupivacaine + fentanyl group. Our observation is similar to the results of Bajwa SS et al[6], who in their study of Clinical profile of levobupivacaine in regional anaesthesia found that the time to onset of sensory and maximum motor block as well as the duration of analgesia is slightly longer with intrathecal levobupivacaine as compared to bupivacaine in caesarean section. In 2014, Del-Rio Vellosilo et al.[10] did a study using $12.5 \mathrm{mg}$ of isobaric bupivacaine and levobupivacaine in two different groups for knee arthroscopy under subarachnoid block. They found that onset of sensory $(p=0.018)$ and motor $(\mathrm{p}=0.003$ ) block was faster in bupivacaine group compared to levobupivacaine group. In 2002, Alley et al[13] conducted a double blind study on 18 healthy volunteers to receive two spinal anaesthetics, one with bupivacaine $(0.5 \%)$ and other with levobupivacaine $(0.5 \%)$ of equal milligram dose $(4,8,12$ $\mathrm{mg}$ ), determined that equal dosage of hyperbaric levobupivacaine and bupivacaine provided a similar sensory and motor response without any specific advantages. Glaser C et al [14] in 2002 conducted a study for elective orthopaedic hip replacement with spinal anaesthesia receiving $3.5 \mathrm{~mL}$ isobaric levobupivacaine $(0.5 \%)$ or $3.5 \mathrm{~mL}$ isobaric bupivacaine $(0.5 \%)$ and found both the drugs had equal effective potencies with regards to onset and duration of sensory and motor blockade. They found that levobupivacaine showed a more sustained sensory and motor blockade. In 2006, Fattorini $\mathrm{F}$ et al[15] conducted a prospective study on 60 patients, scheduled for hip or knee replacement surgery under spinal anaesthesia to receive either $3 \mathrm{~mL}$ levobupivacaine $0.5 \%$ or bupivacaine $0.5 \%$ bupivacaine and found similar onset time both of sensory and motor block between levobupivacaine and bupivacaine and time for regression of motor blockade was also same. In 2008, Mehta A [16] et al compared intrathecal administration of newer local anaesthetic agents ropivacaine and levobupivacaine with bupivacaine in patients undergoing lower limb surgery. Seventy five patients were randomly assigned to receive isobaric intrathecal bupivacaine $15 \mathrm{mg}$, levobupivacaine $15 \mathrm{mg}$, or ropivacaine $15 \mathrm{mg}$. They concluded bupivacaine provided longer duration of analgesia and motor block vs. levobupivacaine and ropivacaine. The levobupivacaine and ropivacaine are an interesting alternative to racemic bupivacaine. In a study on comparison of intrathecal $3.0 \mathrm{~mL}$ isobaric levobupivacaine with $3.0 \mathrm{~mL}$ hyperbaric bupivacaine in elderly patients undergoing TURP or TUR of urinary bladder, Gulec D et al[17] showed that levobupivacaine has statistically significant $(\mathrm{p}=0.0001)$ longer onset of maximum motor block time $(9.84 \pm 3.10$ minutes) as compared to bupivacaine ( $6.49 \pm 2.2$ minutes). Erdil $\mathrm{F}$ et al[11] in their study on the effects of intrathecal levobupivacaine and bupivacaine in 80 elderly patients, came to the conclusion that although the degree of motor block was similar in both the groups, the time to maximum motor block was $19.1 \pm 5.4$ minutes in levobupivacaine group while it was $9.5 \pm 4.2$ minutes in bupivacaine group proving statistically significant longer onset of maximum motor block with levobupivacaine. Our finding is also supported by the findings of Del-Rio Vellosilo et al.[10] who noticed faster onset of maximum motor block in the bupivacaine group compared to levobupivacaine group. Mantouvalou $\mathrm{M}$ et al[18] suggested that onset of maximum motor block was faster in bupivacaine group ( $8 \pm 5 \mathrm{~min}$.) compared to levobupivacaine group (11 \pm 7 min.) using $3 \mathrm{~mL}$ of 0.5 isobaric solution in each group.

Table 2 shows the duration of analgesia in two groups. This duration was calculated by the time between onset of sensory block and administration of first dose of rescue analgesic. Statistically there was significant difference in duration of analgesia among the study groups as ' $p$ ' value is $<0.05$. The mean duration of analgesia in Group L was $124.49 \pm 2.64$ minutes and in Group B was $120.58 \pm 2.51$ minutes. It shows that Group L had longer duration of sensory block than the patients in Group B. Bajwa SS et al[6] demonstrated in their study that duration of analgesia was slightly longer in levobupivacaine group compared to bupivacaine group when used intrathecally in caesarean section. In a study named comparative clinical study between racemic bupivacaine and levobupivacaine in supraclavicular brachial plexus block by Deshpande JP et al,[9] it was shown that the duration of analgesia in levobupivacaine group was $1048.32 \pm 97.24$ minutes and in bupivacaine group was $900.41 \pm 177.74$ minutes. It was significantly longer in levobupivacaine group compared to bupivacaine group ( $p=0.0001)$. In 2012, Turkmen A et al[12] in a prospective study on 50 gravidae undergoing caesarean section who received either bupivacaine $(0.5 \%) 7.5 \mathrm{mg}+$ fentanyl $15 \mathrm{mcg}$ or levobupivacaine $(0.5 \%) 7.5 \mathrm{mg}$ intrathecally concluded longer duration of analgesia in the levobupivacaine + fentanyl group.

Intraoperative and postoperative $\mathrm{HR}$ and MAP were monitored to evaluate haemodynamic stability. Table 3 shows distribution of intraoperative and postoperative pulse rate and MAP and their comparison between two study groups at various time points. Regarding the heart rates there was statistically significant difference between the patients of Group L and Group B as p value was $<0.05$ except at baseline and 30 minutes. Bradycardia was treated with IV atropine 0.3$0.6 \mathrm{mg}$. There was statistically significant difference in mean arterial pressure at all-time points ( $\mathrm{p}$ value $<0.05)$ except at baseline and 20 minutes between the patients of Group L and Group B. Hypotension was treated with IV mephentermine 3$9 \mathrm{mg}$ or phenylephrine $50 \mathrm{mcg}$ and additional lactated Ringer's solution.

Mantouvalou $\mathrm{M}$ et al[18] in their study suggested that there was a slight reduction in mean arterial blood pressures after the spinal injection in all groups, which however was significant only in the bupivacaine group. In addition, the decrease in heart rates after local anaesthetic agent's injection was significant in all groups. Erdil F et al[11] in their study demonstrated that in group bupivacaine, MAP values were significantly lower than in group levobupivacaine, starting from $10 \mathrm{~min}$. until $30 \mathrm{~min}$. after injection; $\mathrm{p}<0.05$. In group levobupivacaine, MAP was significantly lower at 25, 35, 55 and 60 min., compared to baseline; $\mathrm{p}<0.05$. In group bupivacaine, MAP was significantly lower at $5 \mathrm{~min}$. and thereafter, compared to baseline; $\mathrm{p}<0.05$. Throughout the operation, pulse rate was similar in the two groups. However, it was lower in both groups compared to baseline, starting from 25 
min. in group levobupivacaine and $15 \mathrm{~min}$. in group bupivacaine; $\mathrm{p}<0.05$.

Table 4 shows the incidence of side effects in the study groups. Four patients (9\%) in Group L and five patients (11\%) in Group B had incidence of nausea and vomiting. Three patients (7\%) in Group L complained of shivering, whereas the number in Group B was four (9\%).

\section{CONCLUSION}

The present study showed that intrathecal isobaric levobupivacaine $12.5 \mathrm{mg}$ provided late onset of sensory and motor block and longer duration of analgesia compared to hyperbaric bupivacaine $12.5 \mathrm{mg}$ in patients of elective caesarean section. All the patients were haemodynamically stable in both groups.

Thus, in conclusion, levobupivacaine seems to be an effective alternative to intrathecal bupivacaine in infraumbilical surgeries like caesarean section with reduced toxic potential and excellent quality of analgesia.

\section{REFERENCES}

[1] Bernards CM. Epidural and spinal anesthesia. In: Barash PG, Cullen BF, Stoelting RK, et al. eds. Clinical anesthesia. $6^{\text {th }}$ edn. Lippincott Williams \& Wilkins 2009:927-28.

[2] Kleinman W, Mikhail M. Spinal, epidural and caudal blocks. In: Morgan E, Mikhail MS, Murray MJ. edr. Clinical anesthesiology. $3^{\text {rd }}$ edn. Tata McGraw-Hill 2009:290.

[3] Bernards CM. Local anesthetic clinical pharmacology. In: Mulroy MF, Bernards CM, McDonald SB, et al. eds. A practical approach to regional anesthesia. $4^{\text {th }}$ edn. Lippincott Williams \& Wilkins 2009:19.

[4] Foster RH, Markham A. Levobupivacaine: a review of its pharmacology and use as a local anaesthetic. Drugs 2000;59(3):551-79.

[5] McLeod GA, Burke D. Levobupivacaine. Anaesthesia 2001;56(4):331-41.

[6] Bajwa SS, Kaur J. Clinical profile of levobupivacaine in regional anesthesia: a systematic review. J Anaesthesiol Clin Pharmacol 2013;29(4):530-9.

[7] Capogna G, Celleno D, Laudano D, et al. Alkalinization of local anesthetics. Which block, which local anesthetic? Regional Anesthesia 1995;20(5):369-77.
[8] Chung CJ, Choi SR, Yeo KH, et al. Hyperbaric spinal ropivacaine for caesarean delivery: a comparison to hyperbaric bupivacaine. Anesth Analg 2001;93(1):157-61.

[9] Deshpande JP, Ghodaki PS, Sardesai S. Comparative clinical study between racemic bupivacaine and levobupivacaine in supraclavicular brachial plexus block. Indian Journal of Applied Research 2014;4(5):451-4.

[10] Del-Rio-Vellosillo, Garcia-Medina JJ, AbengocheaCotaina A, et al. Spinal anesthesia for knee arthroscopy using isobaric bupivacaine and levobupivacaine: anesthetic and neuro-ophthalmological assessment. Article ID 349034, Biomed Res Int 2014;2014: p. 7.

[11] Erdil F, Bulut S, Demirbilek S, et al. The effects of intrathecal levobupivacaine and bupivacaine in the elderly. Anaesthesia 2009;64(9):942-6.

[12] Turkmen A, Moralar DG, Ali A, et al. Comparison of the anesthetic effects of intrathecal levobupivacaine + fentanyl and bupivacaine + fentanyl during caesarean section. Middle East J Anesthesiol 2012;21(4):577-82.

[13] Allaey EA, Kopacz DJ, McDonald SB, et al. Hyperbaric spinal levobupivacaine: a comparison to racemic bupivacaine in volunteers. Anesth Analg 2002;94(1):188-93.

[14] Glaser C, Marhofer P, Zimpfer G, et al. Levobupivacaine versus racemic bupivacaine for spinal anesthesia. Anesth Analg 2002;94(1):194-8.

[15] Fattorini F, Ricci Z, Rocco A, et al. Levobupivacaine versus racemic bupivacaine for spinal anaesthesia in orthopaedic major surgery. Minerva Anestesiol 2006;72(7-8):637-44.

[16] Mehta A, Gupta V, Wakhloo R, et al. Comparative evaluation of intrathecal administration of newer local anaesthetic agent ropivacaine \& levobupivacaine with bupivacaine in patients undergoing lower limb surgery. The Internet Journal of Anesthesiology 2008;17:1-7.

[17] Gulec D, Karsli B, Ertugrul F, et al. Intrathecal bupivacaine or levobupivacaine: which should be used for elderly patients? J Int Med Res 2014;42(2):376-85.

[18] Mantouvalou M, Ralli S, Arnaoutoglou H, et al. Spinal anesthesia: comparison of plain ropivacaine, bupivacaine and levobupivacaine for lower abdominal surgery. Acta Anaesthesiol Belg 2008;59(2):65-71. 